\title{
Ocorrência de Passalora bougainvilleae (Muntañola) Castañeda \& Braun associado à Bougainvillea spectabilis Willd. em Boa Vista, Roraima
}

\author{
Kátia de Lima NECHET ${ }^{1}$, Bernardo A. HALFELD-VIEIRA ${ }^{2}$ \\ RESUMO \\ O fungo Passalora bougainvilleae é relatado, pela primeira vez, na região de Boa Vista, Roraima, associado a manchas foliares na \\ planta ornamental Bougainvillea spectabilis. As características do fungo são conidióforos agregados em fascículos, emergindo de \\ um estroma subcuticular na face abaxial de lesões velhas. Os conidióforos são lisos, retos, de coloração marrom, não ramificados, \\ maioria asseptados, medindo de $26-57 \mu \mathrm{m} \times 4 \mu \mathrm{m}$. Células conidiogênicas terminais de proliferação simpodial com cicatrizes \\ escuras e pouco espessas. Os conídios são solitários, marrom claro, obclavados, retos a ligeiramente curvos, medindo de 32-70 \\ $\mu \mathrm{m} \times 4-5 \mu \mathrm{m}$, maioria com 3 septos, apresentando um hilo truncado e ápice obtuso.
}

PALAVRAS-CHAVE: Passalora bougainvilleae, Bouganvillea spectabilis, Cercosporioides, Roraima, Amazônia.

\section{Repot of Passalora bougainvilleae (Muntañola) Castañeda \& Braun associated with Bougainvillea spectablis Willd. in Boa Vista, Roraima}

ABSTRACT

The fungi Passalora bougainvilleae is reported, for the first time, Boa Vista, Roraima state, causing leaf spots on ornamental specie Bougainvillea spectabilis. The fungi characteristics are conidiophores hypophyllous in fascicles arising from the upper cells of a stroma subcuticular at old spots. The conidiphores are smooth, straight, pale brown, non-branched, mostly aseptate, $26-57 \mu \mathrm{m} \times 4 \mu \mathrm{m}$. Conidiogenous cells terminal, sympodial with black and thin scars. Conidia solitary, pale brown, obclavate, straight to slightly flexuous, 32-70 $\mu \mathrm{m} \times 4-5 \mu \mathrm{m}, 3$ septate, rounded at apex, truncate at base, with a conspicuous hilum.

KEY-WORDS: Passalora bougainvilleae, Bouganvillea spectabilis, Cercosporoid, Roraima, Amazon.

1 Pesquisador da Embrapa Roraima, Ds. Fitopatologia, katia@cpafrr.embrapa.br

2 Pesquisador da Embrapa Roraima, Ds. Fitopatologia, halfeld@cpafrrembrapa.br 
Bouganvillea spectabilis Willd. (Nyctaginaceae) é um arbusto lenhoso, nativo do nordeste do Brasil, cultivado no mundo todo como ornamental (Lorenzi e Souza, 2001). Em Boa Vista, Roraima, esta planta é freqüentemente encontrada em jardins de áreas residenciais. Em julho de 2003, época de maior precipitação pluviométrica da região, foram observadas, pela primeira vez, folhas de B. spectabilis apresentado alta frequiência de lesões circulares, anfígenas, de coloração brancas, de 1-3 mm de diâmetro, circundadas por um halo marrom escuro (Figura 1). Folhas de B. spectabilis foram coletadas e levadas ao laboratório de Fitossanidade da Embrapa Roraima para observações em microscópio estereoscópio e óptico. Após as observaçōes das estruturas, o patógeno foi identificado como o fungo Passalora e utilizando-se a chave de Medeiros e Dianese (1994) a espécie identificada como Passalora bougainvilleae (Muntañola) Castañeda \& Braun.

O objetivo deste trabalho é descrever as características morfométricas de P. bougainvilleae associada a manchas foliares de B. spectabilis.

Em microscópio estereoscópio observaram-se tufos de conidióforos escuros na face abaxial de lesōes velhas. Após corte do tecido vegetal foram observados, em microscópio ótico, 18-26 conidióforos agregados em fascículos, emergindo das células superiores de um estroma subcuticular, marrom escuro, de tamanho 26-44 (35) x 26-41 (34) $\mu \mathrm{m}$ (Figura $2 \mathrm{~A})$.

Os conidióforos são lisos, marrons claros, retos, não ramificados, a maioria asseptados, raramente com 2 septos, de 26-57 (39) x $4 \mu \mathrm{m}$, com células conidiogênicas terminais de proliferação simpodial, cicatrizes escuras e pouco espessas, refrativas, de 2-3 $\mu \mathrm{m}$ de diâmetro. Os conídios são solitários, lisos, obclavados, marrons claros, retos a ligeiramente curvos, não gutulados, 1-4 septos (maioria com 3 septos), 32-70

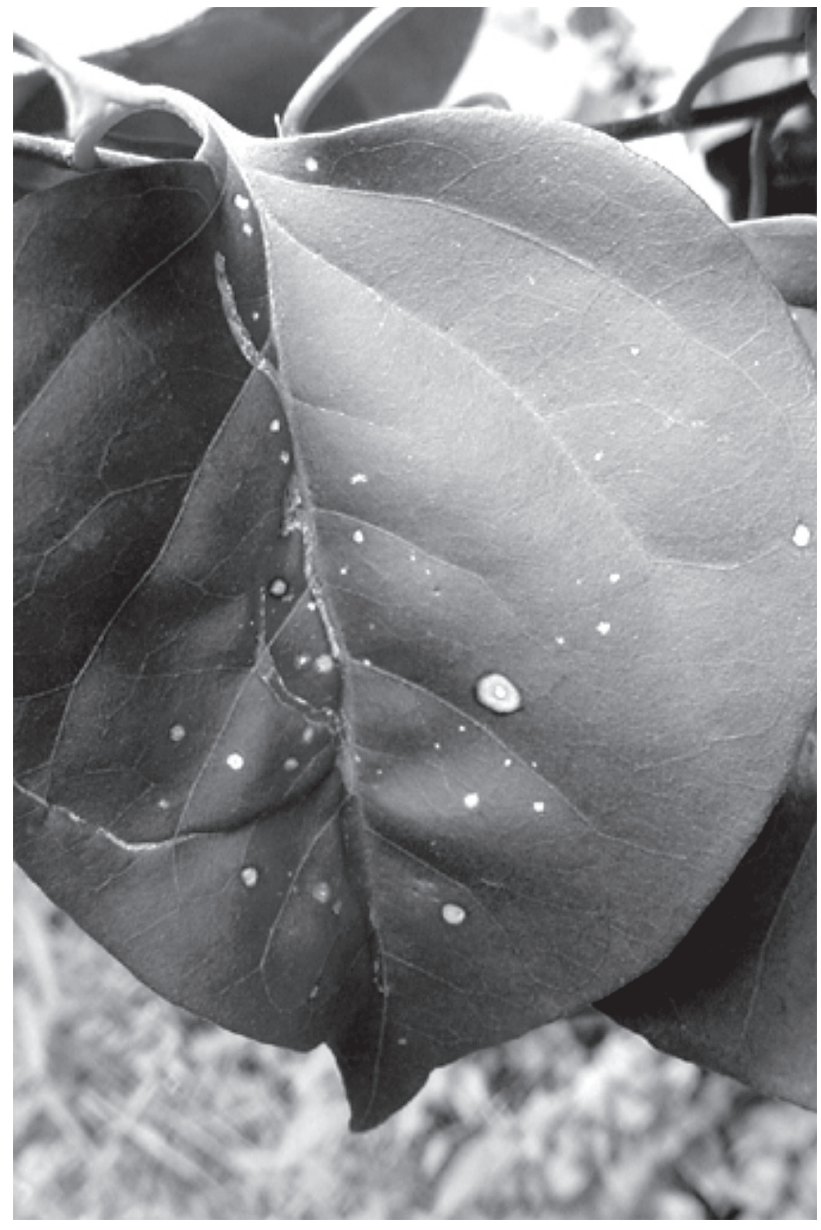

Figura 1 - Sintoma da mancha foliar causada por Passalora bougainvilleae em Bougainvillea spectabilis.

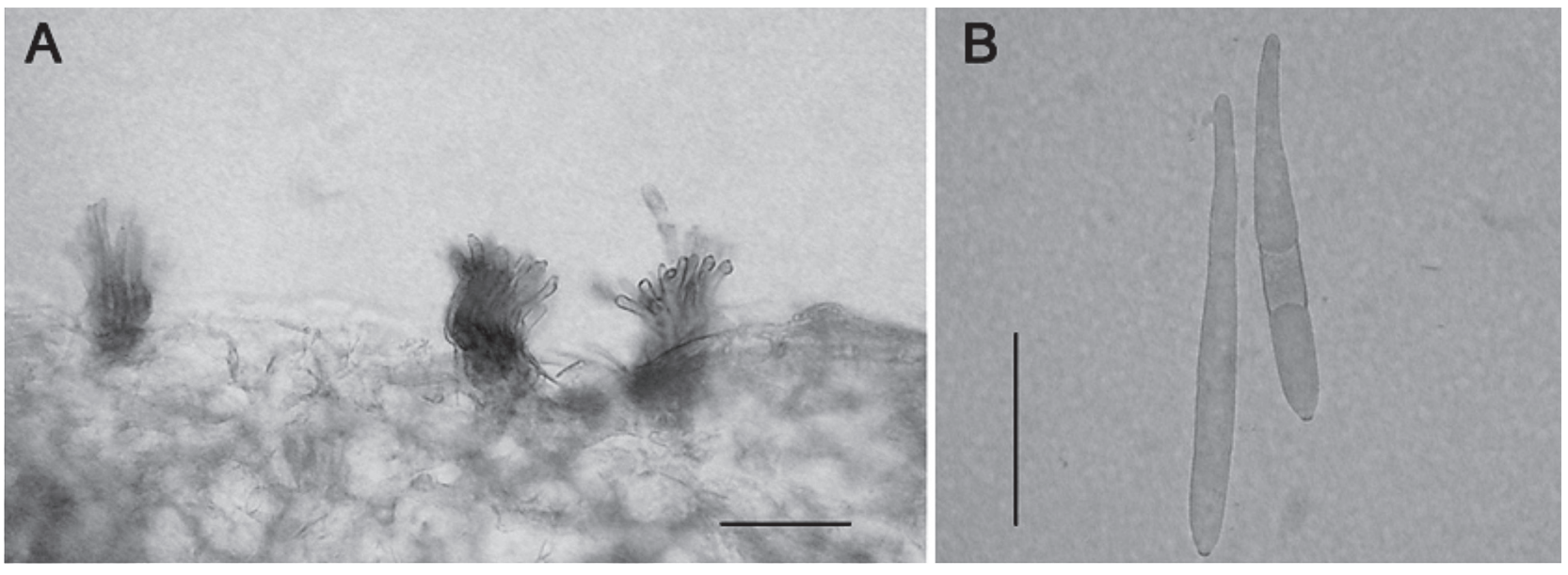

Figura 2 - $A$ = Corte do tecido vegetal mostrando tufos de conidióforos de Passalora bougainvilleae com a formação de conídio. Aumento de 40X (Barra=50 $\mu \mathrm{m}) . \mathrm{B}=$ Conídios de Passalora bougainvilleae. Aumento de 100X (Barra $=30 \mu \mathrm{m})$. 


\section{ACTA}

(47) x 4-5 (4,5) $\mu \mathrm{m}$, com base truncada e ápice obtuso; apresentam um hilo truncado, levemente espesso e refrativo (Figura 2B).

Passalora bougainvilleae foi descrito pela primeira vez em B. spectabilis em Cuba por Braun e Castañeda-Ruiz (1991) cuja denominação anterior era Cercospora bougainvilleae Muntañola. No Brasil, foi primeiramente relatado por Mariano et al. (1989) como Cercospora bougainvillea em Bougainvillea sp. no estado de Pernambuco. Posteriormente, Pereira, Sales \& Dianese (2003) verificaram a ocorrência de P. bougainvilleae associado a manchas foliares na espécie $B$. glabra no Distrito Federal. Este, portanto, é o primeiro registro de $P$. bougainvilleae na região norte do Brasil. Uma vez que a espécie de Bougainvillea não foi identificada quando se fez a descrição original do fungo no país, sugere-se que esta seja a primeira ocorrência da associação do fungo $P$. bougainvilleae com a espécie B. spectabilis no Brasil.

\section{REFERÊNCIAS BIBLIOGRÁFICAS}

Braun, U.; Castañeda-Ruiz, R. 1991. Cercospora and allied genera of Cuba (II). Cryptogamic Botany, 2/3: 289-297.

Lorenzi, H.; Souza, H.M. 2001. Plantas Ornamentais no Brasil. Arbustivas, herbáceas e trepadeiras. Instituto Plantarum, Nova Odessa, São Paulo. 1088p.

Mariano, R.L.R.; Peixoto, A.R.; Holanda, V.T.; Oliveira, S.M.A.; Menezes, M. 1989. Doenças de plantas ornamentais no estado de Pernambuco. Fitopatologia Brasileira, 14 (2): 155.

Medeiros, R.B.; Dianese, J.C. 1994. Passalora eitenii sp. nov. on Syagrus comosa in Brazil and a key to Passalora species. Mycotaxon, LI: 509-513.

Pereira, R.C.; Sales, H.B.; Dianese, J.C. 2003. Ocorrência de Passalora bougainvilleae em folhas vivas de Bougainvillea glabra em Brasília, Distrito Federal. Fitopatologia Brasileira, 28 (supl.): 222.

Recebido em 16/10/2006

Aceito em 19/05/2008 
